\title{
柏林市艺术空间演变与政府引导机制 一一米特区施潘道郊区为例
}

\author{
Development of Art Space and the Mechanism of Government Guidance in Berlin: \\ A Case Study of 'Spandauer Vorstadt' in Mitte
}

梁志超 黄旭 薛德升

Liang Zhichao, Huang Xu, Xue Desheng

摘要: 全球化与后工业化背景下, “创意城市”建设成为研究热点之一。 以柏林市艺术中心区施潘道郊区为例, 关注不同层级政府的作用, 探究 艺术空间的成功引导机制。施潘道郊区经历了多元文化氛围培育、集群 初步形成、空间自我强化与成熟艺术空间形成等四个发展阶段; 政府采 取有效引导策略, 区别于强势管制或放任不顾, 通过正确的角色定位、 长期稳定的土地和财政政策, 创造了灵活的、适宜的、有利的空间发展 条件; 多级政府合作引导, 实现了历史文化街区保护、地方社会网络构 建以及全球创意城市建设等多维目标。

Abstract: Along with post-industrialization and globalization, scholars pay increasing attention to the research on 'Creative City'. Our case study of 'Spandauer Vorstadt' (an art hub in Berlin) traces the roles of multi-level governments in the formation of art space there, exploring related effective policies with respect to their 'guidance strategies'. The development of art space can be divided into four stages, including 'the cultivation of multicultural atmosphere', 'cluster forming', 'self-reinforcing of space' and 'mature art space'. Generally, a dichotomy has been identified - stringent regulation, or "let-it-be". Addressing this divergence, multi-level governments in Berlin have adopted longterm stable policies in the framework of 'guidance strategies' to create flexible, feasible and favorable (3F) conditions for art space. In different stages, multi-level governments play distinctive roles but cooperate with each other to promote the process. Because of these, many achievements have been realized, such as the conservation of historic areas and the formulation of local social networks - as well as 'building a global creative city'.

关键词：创意城市；艺术空间；多级政府；引导机制；柏林市

Keywords: Creative City; Art Space; Multi-level Governments; Guidance Strategy; Berlin

国家自然科学基金国际（地区）交流与合作研究项目 (41320104001), 中山大学高校基本科研业务费专项资金项目 (17lgjc04)

作者: 梁志超, 中山大学城市与区域规划系硕士研究生。1zhich7@163.com 黄旭, 中山大学城市与区域规划系副研究员 薛德升 (通信作者), 中山大学城市与区域规划系教授。 eesxds@mail.sysu.edu.cn

\section{引言}

1912 年约瑟夫 ·熊彼特提出 “创新理论” ${ }^{[1]}$, 强调创新 对经济发展的关键作用。霍克海默等在 1947 年提出了法兰 克福学派的 “文化工业” 概念 ${ }^{[2]}$ 。英国文化部 1998 年发表 了《英国创意产业路径文件》 ${ }^{[3]}$, 明确界定了创意产业的内 涵与划分标准。20 世纪中后期, 西方国家面临传统制造业萎 缩的问题, 生产方式向后福特制转变, 以创意和知识产权为 核心的创意产业逐渐受到各国政府的重视 ${ }^{[4]}$, 文化创意也成 为新时期世界城市发展的重要动力 ${ }^{[5]}$ 。创意阶层开始崛起 ${ }^{[6]}$, 创意空间随之形成。城市作为全球化时代的竞争主体 ${ }^{[7,8]}$, 创 意城市建设成为研究热点。兰德里提出创意城市发展的七要 素 ${ }^{[9]}$, 佛罗里达、霍斯帕斯、格莱泽及科塔等学者也各自提 出创意城市发展的必要条件 ${ }^{[6,10-13]}$ (表 1), 构建了创意城市 经典理论。

\section{表 1 创意城市经典理论观点}

\begin{tabular}{|c|c|c|c|c|c|}
\hline $\begin{array}{l}\text { 经典 } \\
\text { 理论 }\end{array}$ & “七要素” 理论 & $\begin{array}{c}\text { “三因素” } \\
\text { 理论 }\end{array}$ & “3T” 理论 & “3S” 理论 & $\begin{array}{l}\text { “3C" } \\
\text { 理论 }\end{array}$ \\
\hline 学者 & 兰德里 & 霍斯帕斯 & 佛罗里达 & 格莱泽 & 科塔 \\
\hline $\begin{array}{l}\text { 创意 } \\
\text { 城市 } \\
\text { 发展 } \\
\text { 要素 }\end{array}$ & $\begin{array}{l}\text { 创 意品质、领 导 } \\
\text { 力、人的多样性与 } \\
\text { 机遇、组织文化、 } \\
\text { 全球化与本土化协 } \\
\text { 调、空间与基础设 } \\
\text { 施、通讯设施 }\end{array}$ & $\begin{array}{l}\text { 集 中 度、 } \\
\text { 多样性、 } \\
\text { 非稳定性 }\end{array}$ & $\begin{array}{l}\text { 技术、人才、 } \\
\text { 包容度 }\end{array}$ & $\begin{array}{l}\text { 阳光、城市 } \\
\text { 蔓延、技能 }\end{array}$ & $\begin{array}{l}\text { 文化、沟 } \\
\text { 通、合作 }\end{array}$ \\
\hline $\begin{array}{l}\text { 政策 } \\
\text { 要素 }\end{array}$ & $\begin{array}{l}\text { 重视创意人才培 } \\
\text { 养; 城市基础设施 } \\
\text { 建设 }\end{array}$ & $\begin{array}{l}\text { 突发因素 } \\
\text { (危机与冲 } \\
\text { 突) }\end{array}$ & $\begin{array}{l}\text { 针对外来移 } \\
\text { 民、少数族 } \\
\text { 裔、同性恋 } \\
\text { 者等少数群 } \\
\text { 体的包容性 } \\
\text { 政策 }\end{array}$ & $\begin{array}{l}\text { 住 宅 政 策 } \\
\text { ( 控 制 房 } \\
\text { 价、增加住 } \\
\text { 房 供 应); } \\
\text { 城市公共设 } \\
\text { 施的完善 }\end{array}$ & $\begin{array}{l}\text { 公 私 合 } \\
\text { 作 : 政府 } \\
\text { 与创意组 } \\
\text { 织、个体 } \\
\text { 的合作 }\end{array}$ \\
\hline
\end{tabular}

资料来源 : 作者根据参考文献 [6, 9-13] 整理 
在此基础上, 国内外学者对创意空间实践展开研究。国 外实证案例研究集中于城市尺度, 以纽约、伦敦、巴黎、新 加坡市、鹿特丹、阿姆斯特丹、柏林、毕尔巴鄂等典型城 市为案例, 探究创意城市的多样化发展路径 ${ }^{[1422]}$ 。其中, 雅 各布等对柏林市政府在维丁区推行的 “Kolonie Wedding” 项 目进行探究, 发现政府强制干预的开发模式加剧了社会排 斥 ${ }^{[18]}$ 。诺维等以柏林市施普雷河岸媒体区为例加以研究, 发 现政府利用大型项目对创意空间的改造导致了当地文化生 产者的抵抗运动 ${ }^{[19]}$ 。然而, 方田红等对纽约创意街区空间 迁移进行分析, 发现缺乏政府合理干预, 创意街区会向高度 商业化与中产阶级化演变 ${ }^{[20]}$ 。因此, 政府的合理介人与引 导对创意空间的健康发展非常重要。国内的实践案例中, 北 京、上海、广州等城市创意产业发展较快 ${ }^{[23]}$, 相关研究成果 较多 ${ }^{[2428]}$, 侧重于创意产业空间集聚特征及其影响因素探究。 近年来, 不少学者开展小尺度创意空间案例研究。周尚意等 通过研究北京 798、宋庄以及观音堂文化大道等三个北京主 要的美术区, 发现艺术群体对地方政策环境的嵌人是积极 的 ${ }^{[29]}$ 。然而马仁锋等指出: 目前国内创意空间存在 “以创意 之名行地产之实” 等问题 ${ }^{[30]}$ 。具体案例中, 北京 798 和宋庄 存在过度商业化问题 ${ }^{[31]}$, 深圳大芬村缺乏外部制度支撑体 系 ${ }^{[32]}$, 广州红砖厂创意空间建设成为地方政府 “过渡性” 的 逐利行为 ${ }^{[33]}$, 广州小洲村面临 “乡村绅士化” 的挑战 ${ }^{[34]}$, 等。 政府如何有效引导创意空间建设成为关键性问题 ${ }^{[35,36]}$ 。

纵观国内外研究, 现有创意城市理论研究多从国家、城 市等宏观尺度切人, 地方政府在微观尺度层面的作用机制研 究存在缺陷。现有实践案例中, 政府引导容易偏向强势管制 或放任不管, 造成创意空间发展中的过度商业化、绅士化及 本地文化生产者抵抗等问题。本文选取柏林市艺术中心区为 研究对象, 运用质性研究方法, 研究政府在创意空间建设过 程中的作用机制, 以期解析城市创意空间建设中的政府角色 定位, 及其有效引导策略与途径等, 丰富城市创意空间形成 及演进机制等方面的研究内容。

\section{1 柏林市艺术空间格局及施潘道郊区特征}

德国是欧洲重要的创意国家, 2009 年其创意产业总值 超越英国、法国位居欧洲第一位 ${ }^{[37]}$ 。德国国内创意产业生 产总值仅次于汽车工业、机械制造以及金融行业（图 1)。 2010 年德国联邦政府将创意产业分为 11 大类 ${ }^{[38]}$, 艺术产业 是其中一类。作为德国首都及政治文化中心, 柏林市约五分 之一的企业从事创意产业, 全市的艺术家数量居全德首位

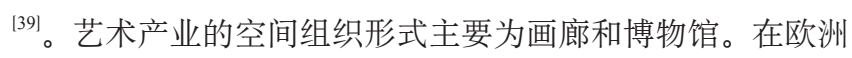

范围内, 柏林市目前拥有的画廊与博物馆数量最多, 已成为 全球当代艺术的中心城市一一全市共计 400 余家画廊, 200 多个博物馆, 6000 多位艺术家 ${ }^{[39]}$ 。2005 年柏林市人选联合 国教科文组织创立的“全球创意城市网络” 1 。柏林市艺术 空间集聚现象明显, 通过定量方法测度, 得出区位基尼系数 (Gi) 为 0.73 , 同时洛伦兹曲线图呈现 “非均衡” 态势 (图 2 ), 表明集聚程度高。70\% 左右的画廊等艺术产业公司集 中于内城的米特区 (Mitte) 及弗里德里希 - 克罗伊茨贝格区 (Friedrichshain-Kreuzberg) 等, 呈现出由外城向内城集聚度 递增的空间规律（图 3)。相较于东西部地区, 艺术空间更 多地分布于接近 “柏林墙” 的中部地区。

本文选取的案例地“施潘道郊区”（Spandauer Vorstadt） 位于柏林市米特区（图 3), 面积 $1.7 \mathrm{~km}^{2}$, 人口约 18500 人 ${ }^{[40]}$ 。 市域层面, 米特区艺术空间集聚程度最高, 并有六大艺术空 间簇群，根据其特点可分为三类 : 第一类为专业化艺术簇群,

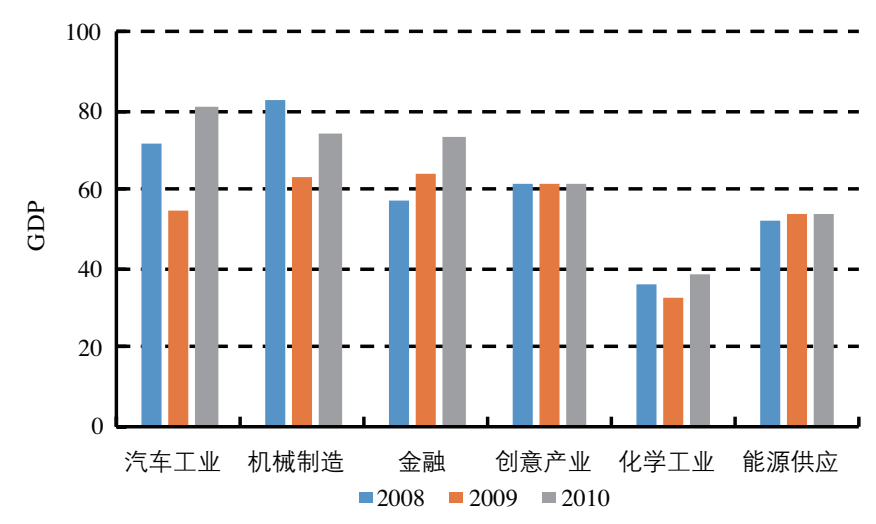

图 1 德国主要行业生产总值 (单位 : 10 亿欧元) 资料来源 : 参考文献 [38]

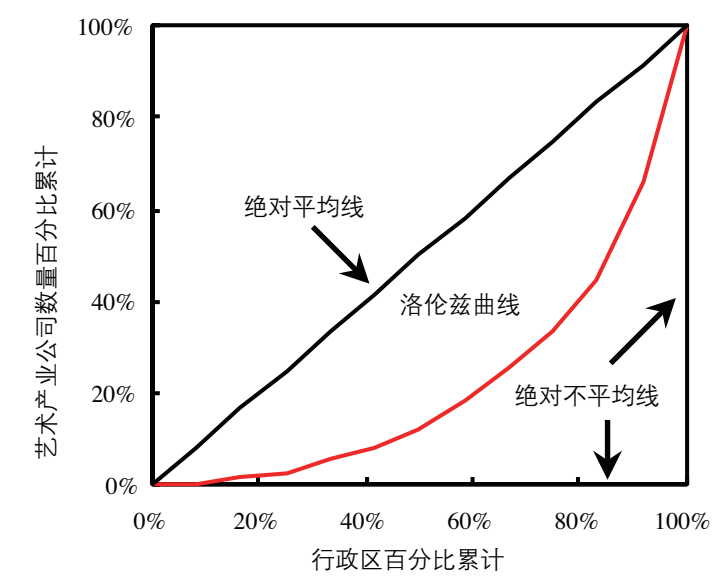

图 22015 年柏林市艺术空间洛伦兹曲线图 资料来源 : 作者根据柏林市创意公司网络平台数据绘制

(1) 可参考联合国教科文组织官方网站: http://www.unesco.org/new/zh/culture/themes/creativity/。 
譬如博物馆岛及案例地; 第二类为遗迹类艺术簇群, 譬如查 理检查站片区; 第三类为商业化艺术簇群, 譬如波茨坦广场、 亚历山大广场及御林广场片区（图 3)。在各艺术簇群中，施 潘道郊区空间面积最大, 艺术家和画廊数量最多, 是柏林当 代艺术的核心区。目前有 90 家左右的画廊集聚此地, 案例 地已成为全市画廊密度最高的街区。此外, 该区曾为著名的 犹太人社区, 亦是柏林市最大的历史街区, 新犹太教堂、哈 克庭院等著名景点分布于此。作为柏林市艺术中心区, 施潘 道郊区兼具艺术专业化、历史文化保护及游览观光等多项职 能, 具有重要的研究意义。

\section{2 数据来源与研究方法}

本文数据来源包括实地调研所得数据, 德国、柏林官方 创意产业发展报告 ${ }^{[37-39]}$ 、柏林市统计年鉴 ${ }^{[40]}$ 、柏林市政府网 站 ${ }^{1}$ 、柏林市创意公司网络平台 ${ }^{(2)}$ 及其他网站。

本文主要采用的研究方法为质性研究—-2015 年 1 月一
2015 年 4 月在德国柏林市开展实地调研, 运用半结构访谈 的方法, 对案例地画廊所有者、艺术家、当地居民及政府工 作人员进行访谈。参与访谈对象共 25 人, 其中画廊所有者 7 人、艺术家 8 人、当地居民 6 人、政府工作人员 4 人（表 2 ）。 此外, 研究结合了文献资料及网站资料等。

\section{3 艺术空间形成过程与政府作用机制}

以五年为一阶段, 图 4 展示了 1990-2015 年间艺术空 间的时空变化情况。案例地画廊空间分布不均衡, 集中分布 于 August 大街、Linien 大街以及 Oranienburger 大街等街道 两侧, 同时新犹太教堂及 “KW” 当代艺术组织等公共文化 场所附近集中分布现象明显。沿主干道的建筑一层房屋和庭 院内部通常为艺术家理想的空间选择, 其中部分空间在工业 时期为厂房 (譬如 “Hackesche Hoefe” 内部画廊、“Sammlung Hoffmann” 画廊等)。总体上画廊集聚在案例地西北片区, 2000 年之后开始有画廊进驻东部片区, 实现了空间拓展, 但

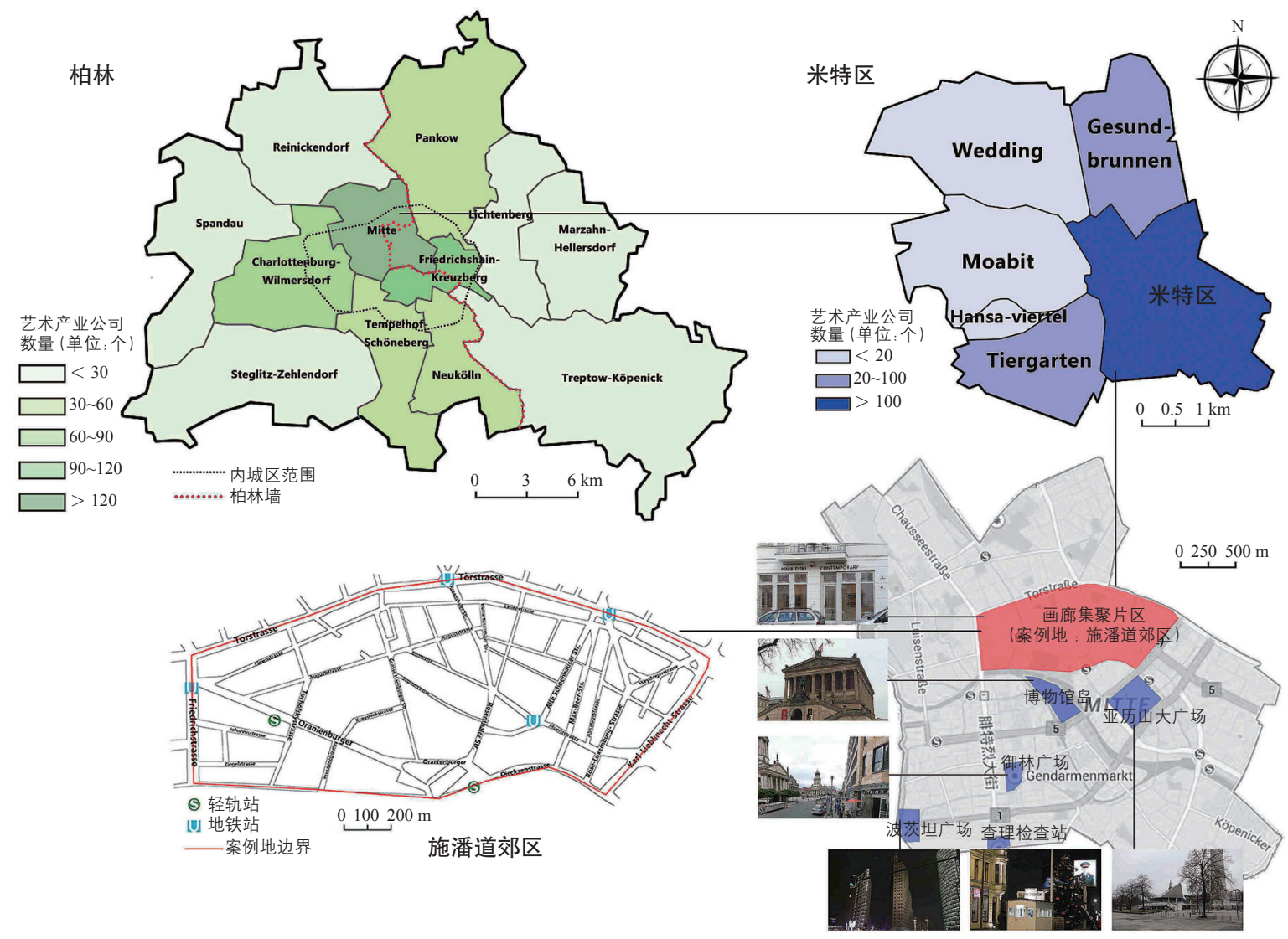

图 3 柏林市艺术空间格局及案例地区位图

资料来源 : 作者根据实地调研及柏林市创意公司网络平台数据绘制

(1) 可参考柏林市政府网站: https://www.berlin.de/。

(2) 可参考柏林市创意公司网络平台 : http://www.creative-city-berlin.de/。 
空间集聚和自我强化效应依然明显。从数量变化特征来看, 艺术空间画廊数量逐年增加, 在 1990 年代初期、2000 年以 及 2010 年左右增长速度快（图 5), 其中具有国际背景的画 廊在 2005 年后数量增加较快。结合案例地最新的土地利用 现状图（图 6), 可以看出画廊多分布于混合型用地以及居 住用地, 极少分布于商业用地。根据案例地画廊空间分布和 数量变化特征, 并结合艺术空间实地调研情况, 可将艺术空 间的形成过程划分为四个阶段。

\section{1 艺术萌芽阶段 (1990 年以前): 艺术多元文化氛围} 培育, 政府力量相对缺乏

犹太文化、东欧文化以及年轻艺术家群体文化是当地文

\section{表 2 访谈对象的基本属性表}

\begin{tabular}{|c|c|c|c|c|c|}
\hline 类别 & 编号 & 职业描述 & 性别 & 年龄 & 所在机构 \\
\hline \multirow{7}{*}{$\begin{array}{l}\text { 画 } \\
\text { 廊 } \\
\text { 所 } \\
\text { 有 } \\
\text { 者 }\end{array}$} & 1 & 画廊老板 & 男 & 43 & $\begin{array}{l}\text { "Galerie Eigen+Art Gmbh\&Co. } \\
K G \text { " 画廊 }\end{array}$ \\
\hline & 2 & 画廊老板 & 男 & 65 & “Sammlung Hoffmann” 画廊 \\
\hline & 3 & 画廊老板 & 女 & 62 & “Galerie Berlin”画廊 \\
\hline & 4 & 画廊经理 & 女 & 32 & “Ifa-gallery" 画廊 \\
\hline & 5 & 画廊经理 & 女 & 50 & “Lumas”画廊 \\
\hline & 6 & 画廊经理 & 男 & 36 & “Podbielski Contemporary” 画廊 \\
\hline & 7 & 画廊经理 & 男 & 31 & “Galerie Christian Nagel” 画廊 \\
\hline \multirow{8}{*}{$\begin{array}{l}\text { 艺 } \\
\text { 术 } \\
\text { 家 }\end{array}$} & 8 & 画家 & 男 & 44 & "Galerie Mojavari” 画廊 \\
\hline & 9 & 画家 & 男 & 39 & “BBK Berlin“艺术家联盟 \\
\hline & 10 & 画家 & 男 & 29 & $\begin{array}{l}\text { “KW Institute for Contemporary } \\
\text { Art” 艺术机构 }\end{array}$ \\
\hline & 11 & 画家 & 女 & 33 & “Jarvis Dooney” 画廊 \\
\hline & 12 & 摄影家 & 女 & 27 & “robertmorat-gallery" 画廊 \\
\hline & 13 & 摄影家 & 男 & 45 & “imago fotokunst” 画廊 \\
\hline & 14 & 视觉艺术家 & 男 & 53 & “LDXArtodrome” 画廊 \\
\hline & 15 & 视觉艺术家 & 女 & 39 & “Ifa-gallery" 画廊 \\
\hline \multirow{6}{*}{$\begin{array}{l}\text { 当地 } \\
\text { 居民 }\end{array}$} & 16 & 教师 & 女 & 51 & 其他 \\
\hline & 17 & 设计公司 & 女 & 31 & 其他 \\
\hline & 18 & 网络公司 & 男 & 29 & 其他 \\
\hline & 19 & 会计 & 男 & 34 & 其他 \\
\hline & 20 & 学生 & 女 & 22 & 其他 \\
\hline & 21 & 工人 & 男 & 35 & 其他 \\
\hline \multirow{4}{*}{$\begin{array}{l}\text { 政府 } \\
\text { 工作 } \\
\text { 人员 }\end{array}$} & 22 & 米特区政府人员 & 男 & 33 & $\begin{array}{l}\text { “KW Institute for Contemporary } \\
\text { Art” 机构负责人 }\end{array}$ \\
\hline & 23 & 米特区政府人员 & 女 & 35 & 米特区政府文化事务部门 \\
\hline & 24 & 柏林市政府人员 & 男 & 46 & 柏林市政府文化事务部门 \\
\hline & 25 & 联邦政府人员 & 男 & 43 & 联邦政府文化事务部门 \\
\hline
\end{tabular}

资料来源 : 作者实地调研
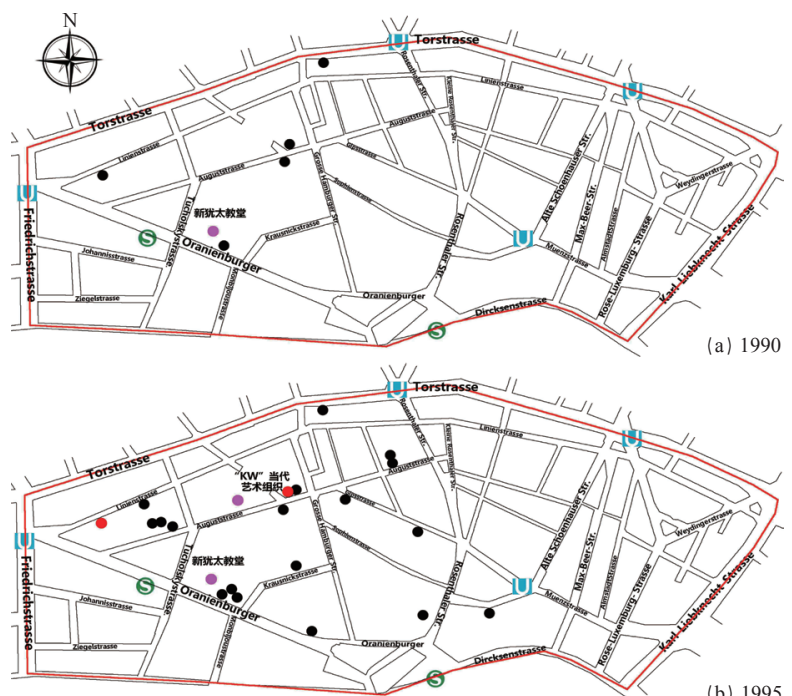

(b) 1995

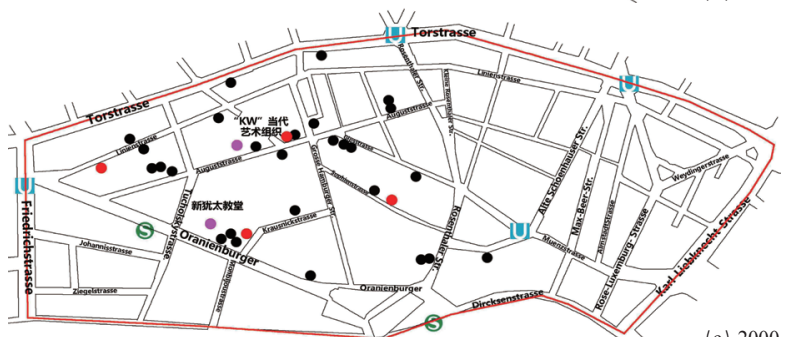

(c) 2000

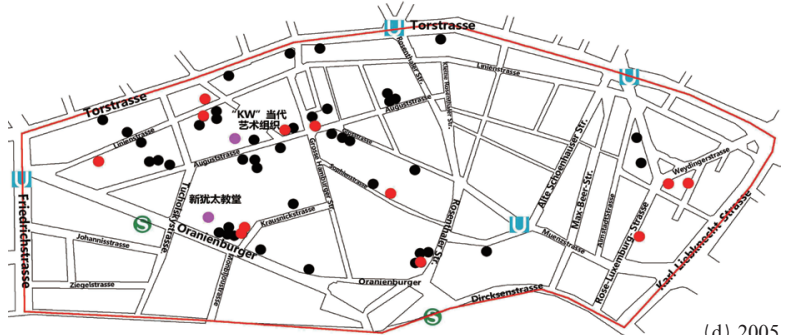

(d) 2005

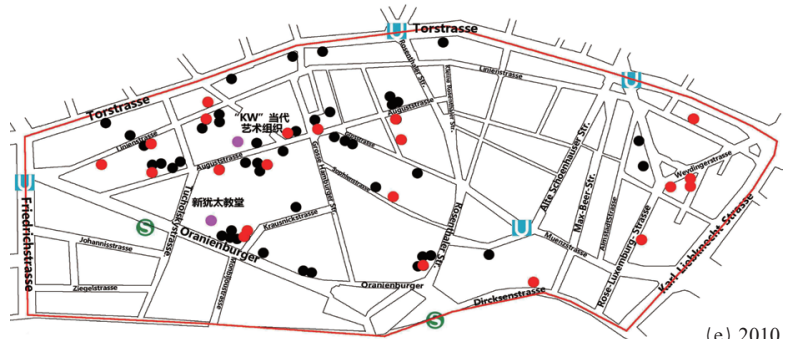

(e) 2010

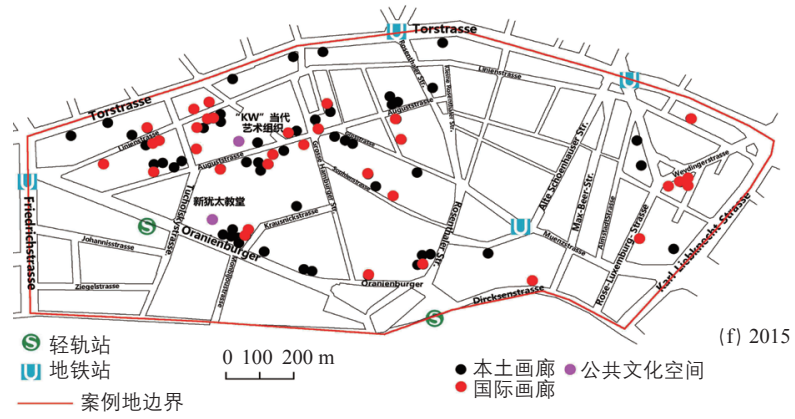

图 4 1990-2015 年案例地艺术空间演变 资料来源 : 同图 3 
化的主要组成部分。20世纪初期, 案例地是柏林市最大的 犹太人社区, 空间上分布着犹太人学校 ${ }^{1}$ 、剧院及教堂, 少 数族裔社区随之形成。虽然街区内大量犹太人二战期间被屠 杀或移民, 但施潘道郊区目前仍有部分犹太人居住, 并留存 有重要的犹太人遗迹（譬如 “Neue Synagoge”, 新犹太教堂）。 与维也纳、阿姆斯特丹等城市案例相似, 犹太文化为案例地 街区文化发展带来有益影响 ${ }^{[41]}$ 。二战后, 柏林被分割为四部 分, 案例地隶属前苏联管辖, 东欧移民在政策引导下迁人该 区,东欧文化元素开始融入地方文化。但由于案例地靠近 “柏 林墙”, 冷战期间被闲置, 中产阶级纷纷迁出。然而, 该街 区的多元文化氛围、低成本的消费却吸引着年轻艺术家不断 进驻。

总体上，该阶段街区的艺术空间集群尚未形成，空间主 要作用者为少数族裔、外来移民及年轻艺术家群体, 政府对 艺术空间干预少。街区居民自发形成的多元文化氛围，为艺 术创作提供了丰富的文化素材。

\section{2 快速发展阶段（1990-2000 年）: 艺术空间集群初 步形成, 政府间接引导}

二战及冷战期间的政治突发因素，导致街区缺乏政府和 私人部门的投资, 造成了街区衰退，1990 年街区人口总数 不及 7000 人。柏林重新统一后, 地区人口流动出现两大新 流向：一是由于经济水平差异, 柏林市内部呈现东柏林人口 向西柏林流动的特点; 二是柏林市周边地区如勃兰登堡州等 地区人口流向柏林, 其中不乏艺术家。“Galerie Berlin”画廊 和 “Galerie Eigen+Art Gmbh \& Co.KG” 画廊的创立者均在这 样的背景下分别于 1990 年和 1992 年由东德迁至施潘道郊区。 随着案例地画廊和艺术家的增多, 1992 年当地艺术家群体
成立了自我管理与组织的艺术机构— “ $\mathrm{KW}$ ”当代艺术组 织。与此同时, 当地居民逐渐认可并接纳了艺术家群体, 部 分居民将一楼闲置房屋修缮后出租给艺术家作为画廊或工作 室 (第 16、17、19 号受访者)。街区的再复兴受到政府的关 注，1992 年市政府成立官方机构 “国家历史遗迹保护办公 室”, 并通过《柏林市历史遗迹保护法案》将案例地列为历 史文化街区进行保护。1993 年市政府将该区列为城市更新 区域, 并采取了 “谨慎城市更新” 的策略 ${ }^{142]}$ 。更新改造经费 由市政府承担, 更新目标为提升区域居住功能并引导艺术产 业发展, 更新项目集中于案例地的中西部。当地政府期望通 过文化艺术的发展路径复兴街区。1990 年代中期, 施潘道 郊区成为地租低廉、基础设施完善并拥有多元文化氛围的街 区, 是艺术家理想的创作与生活空间。在米特区政府引导下, 艺术家与当地居民的互动关系更为密切, 形成了稳定的社会 网络。第 2 号受访者于 1994 年迁人案例地, 其工作室是通 过区政府引介, 以较低租金向原居民租借到的。作为对当地 社区的回馈, 他们每周六会向社区邻里展示并讲解艺术藏品。 第 3 号受访者一一某画廊负责人提到与社区居民的互动 :

“周边居民能够在这里找到他们钟爱的艺术品, 每一个人 在离开画廊的时候都会比进来时更开心, 画廊已成为社区的公 共艺术空间。”

在联邦政府资助下, 1998 年德国联邦文化基金会在案 例地举办了柏林第一届 “Berlin Biennale” 艺术大会 ${ }^{2}$ 。

该阶段艺术空间集群初步形成, 案例地超过五分之二的 画廊是在本阶段进驻的, 画廊集中分布于西部片区。空间作 用者包括联邦政府、柏林市政府、米特区政府、艺术家群体 和当地居民。该阶段体现出政府正确的角色定位, 是服务者、 协调者而非逐利者。政府服务于案例地旧城更新、基础设施

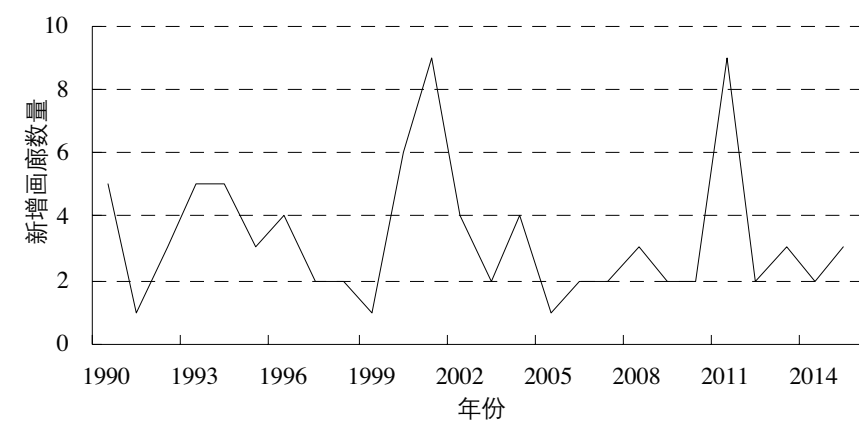

图 5 1990-2015 年案例地每年新增画廊数量 资料来源 : 同图 3

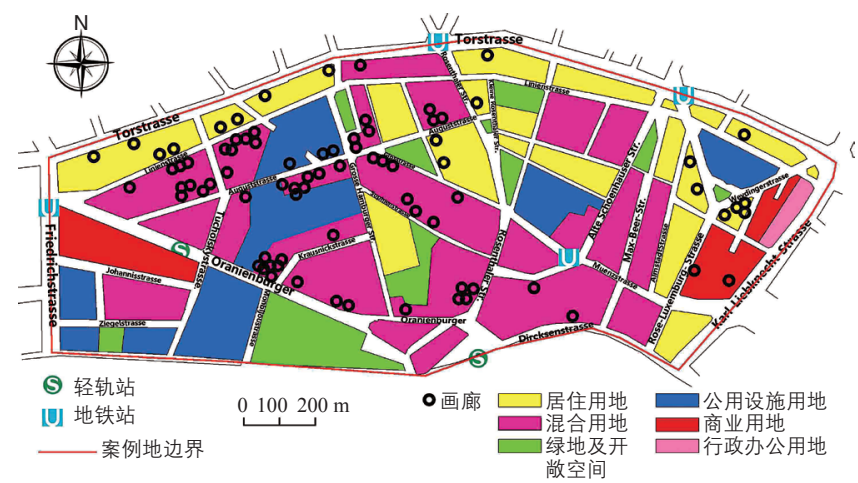

图 62015 年案例地土地利用类型图

资料来源 : http://www.stadtentwicklung.berlin.de/

(1) 画廊“Museum THE KENNEDYS”成立于 2009 年, 地址为 Auguststraße 11/13, 是犹太人女子学校旧址。

(2) 柏林市于 1998 年举办了第一届Berlin Biennale 当代艺术大会, 由德国联邦政府统筹, 由德国联邦文化基金会 (Kulturstiftung des Bundes) 出资承办。 
建设; 充分尊重街区历史与现状, 重视对地方文脉的保护; 协调艺术家群体与当地居民的社会网络关系, 营造了良好的 艺术氛围。

\section{3 空间拓展阶段（2001一2010 年）: 艺术空间自我强 化, 政府直接引导}

21 世纪初, 在后工业化背景下, 柏林市特别是内城地 区面临产业结构转型的挑战, 内城复兴的重要策略之一即为 培育创意文化产业, 政府开始直接参与艺术空间的引导。与 此同时, 艺术空间也在进行自我强化。施潘道郊区的画廊通 常为中小规模, 空间集聚有利于形成良好的集群效应和品牌 效应; 同时便于艺术家群体共享周边空间资源, 譬如俱乐部、 设计公司等; 此外, 集聚能够满足艺术家及时交流创作想法 并获取展会信息的需求。上述因素影响下, 艺术空间集聚不 断加强。除艺术家外, 相关行业的从业者也参与了本阶段的 作用过程, 空间上形成了多样化的产业结构 ${ }^{[43]}$ 。俱乐部、时 尚餐厅的从业者为艺术家提供了交流创作灵感的开放空间, 艺术精品店完成了创意街区 “媒介一空间辩证法” 中 “媒介 的物化” 这一过程 ${ }^{[44]}$, 共同推动了艺术空间的演变。对于街 区自行建构的社会网络, 当地政府采取协调与合作的发展策 略。2002 年, 联邦政府及市政府共同资助 “KW” 当代艺术 组织,并委托其主办德国当代艺术大会 “柏林双年展” (Berlin Biennale), 同时促进该组织与国内外艺术机构 ${ }^{1}$ 的广泛合作, 该组织已被视为柏林市作为世界当代艺术中心的重要标志

(第 10、22 号受访者)。米特区政府参与对 “ $K W ”$ 当代艺 术组织、“BBK Berlin” 艺术联盟 ${ }^{(2)}$ 及 “LVBG” 柏林画廊组 织 ${ }^{3}$ 等机构的日常管理 ; 2004 年区政府开始与本地艺术联盟 共同筹办 “Gallery Weekend Berlin” 画廊周。2005 年, 在联 邦政府和市政府的共同努力下, 柏林市人选 “全球创意城市 网络”。此外, 联邦政府财政部门及文化事务部门开始为艺 术家和画廊提供专项补贴, 用于建设工作室和筹办展会, 并 实行税收优惠政策。2008 年金融危机时期, 为维持行业稳 定, 画廊和个体艺术家只需为营业额的 $30 \%$ 部分缴税（第 1、4、5、8 号受访者)。为配合艺术空间拓展, 市政府规划 部门对案例地尚未修复完善的东部片区进行更新改造。在此 过程中, 不断有新画廊进驻, 并且新进驻画廊中很多具有国 际背景。国际著名画廊 “Galerie Christian Nagel” 于 2002 年 由科隆迁至柏林, 全球连锁艺术机构 “Lumas”于 2004 年
在 “Hackesche Hoefe” 庭院开设画廊。第 7 号受访者一 “Galerie Christian Nagel” 画廊的负责人在接受访谈时说 :

“我们选择迁到这里, 主要看重的是这里的年轻艺术家群 体, 跨文化视角的艺术建构以及地方政府的支持……这些对于 先锋艺术有着重要意义。”

第 8 号受访者一一某伊朗籍艺术家在回答关于艺术空 间集聚的问题时讲到：

“如果去分析为什么大家会集聚到这里, 正如在文艺复兴 时期, 达芬奇、毕加索、提香都集聚在佛罗伦萨一样, 现在我 们都来到了这里。”

本阶段艺术空间集群不断强化, 空间拓展至东部片区, 主要作用者包括联邦政府、柏林市政府、米特区政府、艺术 家群体及当地居民。政府服务于艺术产业链的各环节并给予 政策支持 : 艺术创作阶段, 通过财政补贴和专项资金帮助艺 术家创建画室; 艺术生产阶段, 予以灵活的税收减免政策; 艺术作品推广阶段, 给予筹备展会及对外艺术交流的经费支 持。长期稳定的财政政策保证了艺术空间的平稳发展。

\section{4 稳步发展阶段（2011一2015 年）: 成熟艺术空间形 成, 政府引导策略保持稳定}

2011-2015 年, 案例地新增画廊 19 个, 选址基本都在 早期画廊集聚片区，空间格局变化不大。与前几个阶段不同 的是 : 本阶段不仅有新画廊进驻, 同时出现个别画廊迁出 ${ }^{(4}$ 。 总体上呈现动态平衡、稳步发展的空间态势。

长期稳定的土地和财政政策 : 柏林市政府保证了用地 类型与土地相关政策的长期稳定, 避免了艺术空间出现 “绅士化”与过度商业化等现象。为此, 市政府专门成 立 “Atelierbeauftragter” 机构以调控艺术空间地租, 防止 租金过快上涨。施潘道郊区有 25 家画廊经营时间超过 20 年, 约有 60 家超过 10 年。对比 2000 年和 2015 年土地 利用现状图（图 7), 可以清晰地看出：15 年间基本没有 用地类型的调整，居住用地并未被商业用地取代。对比国 内广州市某创意产业园案例 ${ }^{5}$, 政府限制园区企业土地使 用年限, 并期望通过更改园区土地性质获得 “二次收益”, 不稳定的土地政策引起了创意企业的 “短视” 和逐利行 为。而在财政政策方面, 联邦政府和市政府继续给予对应 资助。

艺术空间的全球化体现在艺术个体、艺术协会及艺术

(1) 包括国际著名的艺术机构: “Venice Biennial” “Documenta” 以及 “Hybrid Workspace”等。

(2) “BBK Berlin”为柏林视觉艺术家联盟, 可参见 http://www.bbk-berlin.de/ 网站信息。

(3) LVBG (Landesverband Berliner Galerien) 为柏林本地画廊组织。

(4)“Gitteweisegallery”画廊 2011 年迁至澳大利亚悉尼; “Croynielsen”画廊 2014 年迁至奥地利维也纳。

(5)根据实地调研, 该创意园区土地使用年限为 20 年, 园区用地现为工业用地, 政府计划改为商业用地。 
城市三个层面。个体层面, 新进驻画廊多具有国际背景, 譬如 “LDXArtodrome” 画廊 ${ }^{1}$ 在马耳他和中国均有分店, “Podbielski Contemporary” 画廊 ${ }^{(2)}$ 由巴塞罗那迁移至此, “Jarvis Dooney”画廊 ${ }^{3}$ 来自澳洲。个体艺术家的国际交流日益频繁, 本地画廊融合了全球化的艺术元素, 譬如 “Ifa-gallery” 画廊于 2015 年 3 月举办 “世界当代中小学学校建筑艺术展”, 展示 了亚洲、非洲、欧洲及拉美等地区案例, 其中中国福建省下 石村桥上书屋案例人选展会。协会层面, 在 1998 年创办 “柏 林双年展”当代艺术大会、2004 年举办首届 “柏林画廊周”

(Gallery Weekend Berlin) 的基础上, 2012 年柏林市政府又推 出“柏林艺术周” (Berlin Art Week) 活动, 由柏林市参议院 政府经济事务与文化事务部提供资金, 艺术周期间举办了国 际艺术大会—“abc-Art Berlin Contemporary” “Preview Berlin Art Fair” 及 “Artfi-The Fine Art \& Finance Conference” 等, 旨 在探讨国际艺术市场未来的发展趋势。2015 年画廊周活动共 有 15 家合作企业, 其中超过三分之二是国际艺术公司。此外, 联邦政府对艺术个体和艺术协会的国际交流给子了专项资金 支持。城市层面，在人选 “全球创意城市网络” 的基础上， 柏林市将艺术空间发展与创意城市建设相结合, 将艺术作为 柏林市的文化标签, 吸引国际艺术家与艺术爱好者进驻与交 流。而艺术空间自身也成为旅游目的地, 吸引世界各地的游 客前来参观, 案例地的哈克庭院 ${ }^{(4)}$ 、新犹太教堂即为柏林市 著名的旅游景点。根据米特区文化事务部门调研数据, 参观 案例地画廊的人群中, 有 $60 \%$ 左右来自其他国家。柏林市将 本土化的艺术实践放置于国际化的艺术语境中，提升了艺术 空间的全球化水平。

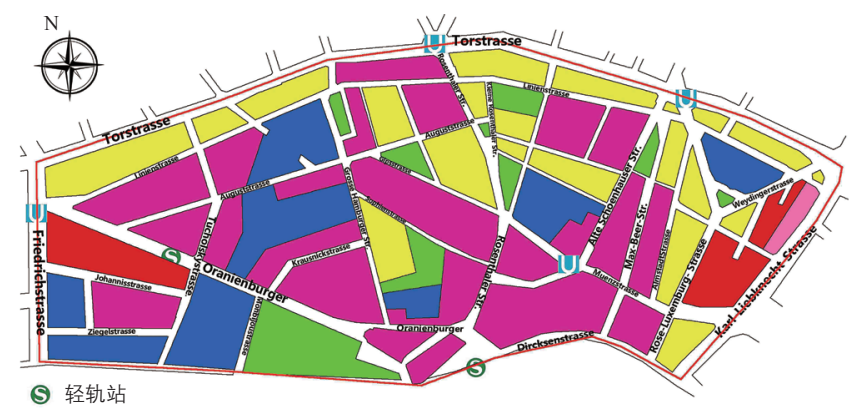

$$
\text { UI地铁站 }
$$

\section{5 政府作用机制：多层级、多维度建设艺术空间}

艺术空间发展初期, 多元文化氛围的培育需要相对宽 松的管制环境, 政府参与度低。快速发展阶段, 基于街区再 复兴的发展诉求, 柏林市政府适时介人艺术空间引导并积极 推行城市更新 ; 区政府作为 “中介角色” 协调原居民与进驻 艺术家群体的关系。空间拓展阶段, 柏林市内城产业结构面 临调整, 案例地艺术群体的“自组织”也逐渐成熟, 区政府 参与并指导各艺术群体的日常运作; 联邦政府主要给予财政 支持; 市政府对案例地东部片区进行改造, 带动了艺术空间 的拓展, 并与联邦政府合作帮助柏林市人选 “全球创意城市 网络”。稳步发展阶段, 市政府推行了长期稳定的土地政策, 并与联邦政府共同资助国际性的艺术交流活动, 将本土化的 艺术实践放置于全球化的艺术语境中（表 3)。艺术空间不同 发展阶段中所体现出的政府引导策略, 一定程度上回应了不 同创意城市经典理论中的政策部分 : 艺术萌芽阶段多元文化 氛围的培育印证了霍斯帕斯 “三要素” 中的多样性要素 ${ }^{[11]}$; 快速发展阶段推行的城市更新政策回应了兰德里 “七要素” 中的基础设施建设部分 ${ }^{[9]}$; 空间拓展阶段中的政府政策体现 了 “3C” 理论中强调的政府与艺术组织的有效合作 ${ }^{[13]}$ 。但以 往创意城市经典理论研究多为静态的空间描述, 并未阐释清 楚政府在创意空间生命周期的各个阶段应如何进行引导。实 际上, 创意空间的发展具有一定的路径依赖和演化特性, 空 间引导需要与之协调。将时间序列的实证与创意空间的演化 发展特性相结合, 能够更好地把握创意空间的发展规律。

作为德国三大 “城市州” 之一, 柏林市行政管辖层级包 括联邦政府、柏林市政府以及米特区政府等 ${ }^{5}$ 。艺术空间发 展过程中, 各级政府分工明确、因势利导 : 联邦政府主要给

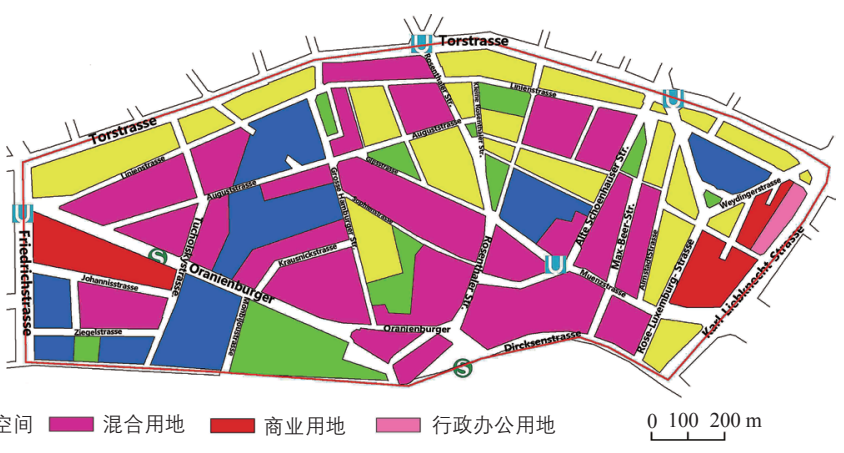

图 7 案例地土地利用现状图 (左 : 2000 年, 右 : 2015 年)

资料来源 : 同图 6

(1) “LDXArtodrome”画廊由华裔所开, 又名龙德轩画廊, 2013 年迁至案例地。

(2) “Podbielski Contemporary”画廊 2005 年开设于圣地亚哥, 2006 年迁至巴塞罗那, 2011 年迁至案例地。

(3) “Jarvis Dooney”画廊以澳大利亚和新西兰艺术风格为主, 2013 年迁移至案例地。

(4) 哈克庭院德文名为 “Hackesche Höfe”, 地址为 Rosenthaler Str. 40-41。

(5) 作为联邦制国家, 德国行政体系可以分为联邦、州、地方、市 (县)、行政区等不同行政层级 ${ }^{[46]}$ 
表 3 艺术空间不同发展阶段中各级政府的引导策略

\begin{tabular}{|c|c|c|c|c|}
\hline 发展阶段 & 政府参与程度 & 空间主要作用者 & 引导政策 & 政策效果 \\
\hline $\begin{array}{l}\text { 艺术萌芽阶段 } \\
\text { (1990 年之前) }\end{array}$ & 低 & $\begin{array}{l}\text { 少数族裔、外来移民、年轻艺 } \\
\text { 术家群体 }\end{array}$ & 二战、冷战等政治突发因素（其他） & 艺术空间多元文化氛围形成 \\
\hline $\begin{array}{l}\text { 快速发展阶段 } \\
(1990-2000 \text { 年) }\end{array}$ & 较高 & $\begin{array}{l}\text { 联邦政府、柏林市政府、米特 } \\
\text { 区政府、外来移民、艺术家群体、 } \\
\text { 当地居民 }\end{array}$ & $\begin{array}{l}\text { 柏林统一等政治突发因素（其他）; 历史街区保护与城市更 } \\
\text { 新项目 (市政府); 协调原居民与艺术家关系 (区政府); 举 } \\
\text { 办艺术大会 (联邦政府) }\end{array}$ & $\begin{array}{l}\text { 历史街区保护; 外来艺术家 } \\
\text { 进驻 ; 街区硬环境改善 ; 艺 } \\
\text { 术集群初步形成 }\end{array}$ \\
\hline $\begin{array}{l}\text { 空间拓展阶段 } \\
\text { (2001－2010年) }\end{array}$ & 高 & $\begin{array}{l}\text { 联邦政府、柏林市政府、米特区 } \\
\text { 政府、艺术家群体、当地居民 }\end{array}$ & $\begin{array}{l}\text { 柏林市产业结构调整（市政府）；对艺术个体或行业的资助 } \\
\text { (联邦政府)；对案例地东部片区更新改造（市政府）；管理 } \\
\text { 艺术机构并开展合作（区政府） }\end{array}$ & $\begin{array}{l}\text { 艺术空间集聚加强; 避免经 } \\
\text { 济危机影响 ; 人选 “全球创 } \\
\text { 意城市网络”; 艺术空间拓展 }\end{array}$ \\
\hline $\begin{array}{l}\text { 稳步发展阶段 } \\
\text { (2011一-2015年) }\end{array}$ & 高 & $\begin{array}{l}\text { 联邦政府、柏林市政府、米特 } \\
\text { 区政府、艺术家群体 }\end{array}$ & $\begin{array}{l}\text { 长期稳定的土地政策（市政府）; 长期稳定的财政支持（联 } \\
\text { 邦政府 /市政府); 艺术全球化政策导向（联邦政府/市政府） }\end{array}$ & $\begin{array}{l}\text { 艺术空间稳步发展；艺术空 } \\
\text { 间全球化程度提高 }\end{array}$ \\
\hline
\end{tabular}

资料来源 : 根据实地调研资料整理

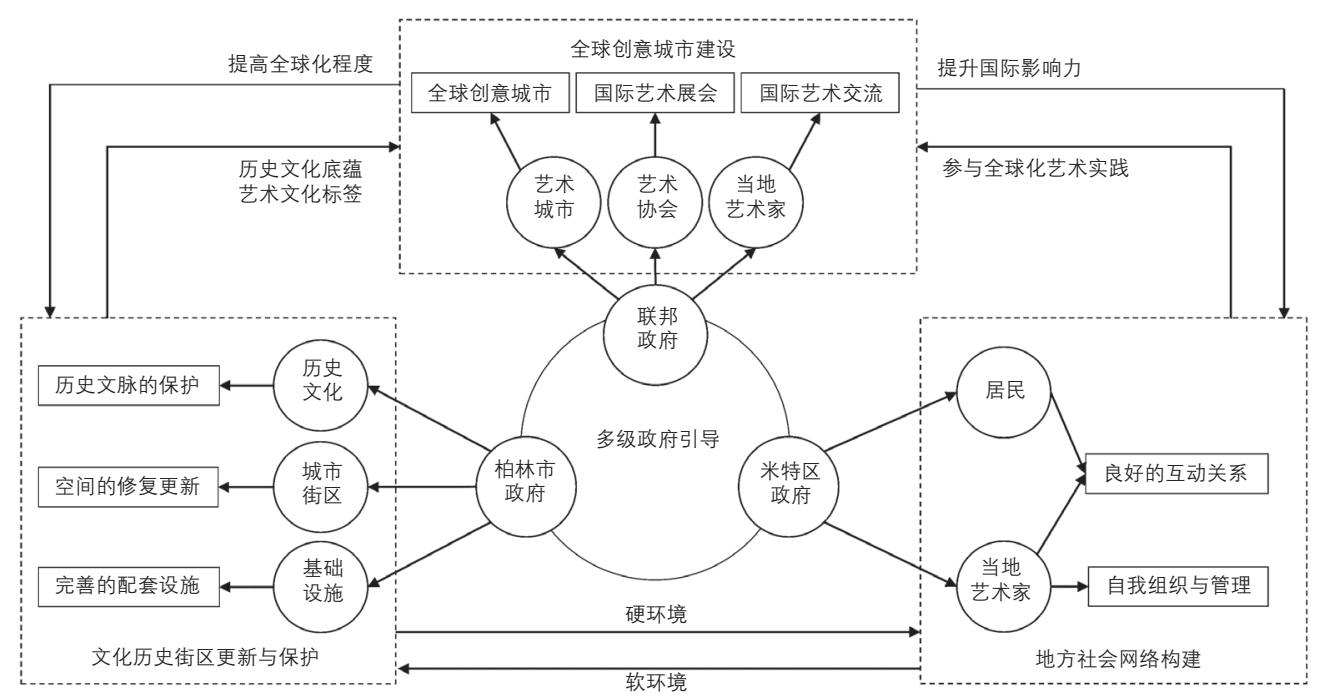

图 8 多层级、多维度建设艺术空间

资料来源 : 作者绘制

予财政支持, 包括艺术行业的税收优惠、艺术组织运营的经 费支持以及国际艺术交流专项资金扶持等 ; 柏林市政府除财 政支持外, 承担了街区城市更新、历史文化保护及其他规划 管理工作; 米特区政府主要负责协调当地社会网络、管理艺 术组织等工作。通过多级政府的协调配合, 实现了历史文化 街区保护、地方社会网络构建以及全球创意城市建设等多维 目标 (图 8)。

\section{4 结论与讨论}

施潘道郊区艺术空间的发展过程经历了艺术多元文化氛 围培育、艺术空间集群初步形成、艺术空间自我强化以及成 熟艺术空间形成等四个阶段。不同层级政府、艺术家、本地 居民与外来移民成为艺术空间形成过程中的主要作用者, 不 同发展阶段空间作用机制存在差异, 各作用者的参与程度亦 有不同。
政府既没有放松管制，也没有强势管制或过度干预艺术 空间的发展, 而是采取了积极有效的引导策略。政府角色定 位清唽准确, 摒弃了 “企业化地方政府” ${ }^{[33,45]}$ 概念框架下的 逐利属性, 选择基于服务者和协调者角色下的有效引导的空 间策略, 充分发挥政府资源优势, 为艺术空间的发展创造了 灵活的、适宜的、有利的发展条件。政府的土地政策和财政 政策长期稳定，避免了“朝令夕改”所造成的艺术企业 “短 视” 和逐利行为, 避免了艺术空间过度商业化等问题, 有利 于艺术氛围的保持、艺术集群的形成及艺术品牌的打造。

多层级政府合作引导, 多维度建设艺术空间。不同层级 政府在艺术空间不同发展阶段参与程度不同，在不同阶段采 取的政策存在差异。当地政府充分尊重街区历史及地方社会 网络, 并与当地文化组织开展合作, 协调当地居民与艺术家 群体的关系; 发挥不同层级政府的优势共同引导, 将艺术空 间发展与创意城市建设相结合, 将本土化的艺术实践放置于 
国际化的艺术语境中。

本文从政府政策视角切人, 开展小尺度实证研究, 对当 地政府在施潘道郊区艺术空间发展中的作用机制进行了过程 性探究, 解读出以往大尺度研究并未阐释清楚的政策引导内 容。但由于中国与西方国家的政治体制与政治环境存在差异， 同时中国开始创意城市建设的实践工作相对较晚，创意城市 的理论基础和实践基础均有别于西方国家。因此，对于西方 创意城市建设的政策引导经验，中国地方政府应在借鉴的基 础上加人对本土化要素的考量。 UPI

\section{参考文献}

[1] 约瑟夫 · 熊彼特. 经济发展理论 [M]. 北京：中国商业出版社, 2009.

[2] Max H, Adorno T W. Dialectic of Enlightenment, Philosophical Fragments[M]. Stanford: Stanford University Press, 2002.

[3] Creative Industries Mapping Document 1998[M]. London: GB Department of Culture, Media and Sport, 1998.

[4] 格罗斯曼. 全球经济中的创新与增长 [M]. 北京: 中国人民大学出版社, 2003.

[5] 黄鹤绵, 朱虹, 薛德升. 境外世界城市文化动力研究综述与启示 [J]. 热 带地理, 2014(3): 319-326.

[6] Florida R. The Rise of Creative Class[M]. New York: Basic, 2002.

[7] 克拉克, 费尔德曼, 格特勒. 牛津经济地理学手册 [M]. 北京: 商务印书 馆, 2005.

[8] 藤田昌久, 保罗・克鲁格曼. 空间经济学：城市、区域与国际贸易 [M] 北京: 中国人民大学出版社, 2011.

[9] Landry C. The Creative City: A Toolkit for Urban Innovators[M]. London: Earthscan Publications, 2000.

[10] Florida R. Cities and the Creative Class[J]. City \& Community, 2003, 2(1): 3-19.

[11] Hospers G J. Creative Cities in Europe[J]. Intereconomics, 2003, 38(5): 260269.

[12] Glaeser E. Review of Richard Florida's The Rise of the Creative Class[J]. Regional Science and Urban Economics, 2005, 35(5): 593-596.

[13] Maurizio C. Culture, Communication and Cooperation: The Three Cs for a Proactive Creative City[J]. International Journal of Sustainable Development, 2009, 12(2): 124-133.

[14] Chang T C. Renaissance Revisited: Singapore as a 'Global City for the Arts' [J]. International Journal of Urban and Regional Research, 2000, 24(4): 818-831.

[15] Mommaas H. Cultural Clusters and the Postindustrial City: Towards the Remapping of Urban Cultural Policy[J]. Urban Studies, 2004, 41(3): 507-532.

[16] Colomb C. Pushing the Urban Frontier: Temporary Uses of Space, City Marketing, and the Creative City Discourse in 2000s Berlin[J]. Journal of Urban Affairs, 2012, 34(2): 131-152.

[17] Lange B, Kalandides A, Stöber B, et al. Berlin's Creative Industries: Governing Creativity?[J]. Industry and Innovation, 2008, 15(5): 531-548.

[18] Jakob D. Constructing the Creative Neighborhood: Hopes and Limitations of Creative City Policies in Berlin[J]. City, Culture and Society, 2010, 1(4): 193-198.

[19] Novy J, Colomb C. Struggling for the Right to the (Creative) City in Berlin and Hamburg: New Urban Social Movements, New 'Spaces of Hope' ?[J]. International Journal of Urban and Regional Research, 2013, 37(5): 1816-1838.

[20] 方田红, 曾刚, 张云伟. 纽约自发性创意街区空间迁移原因分析 [J]. 城 市问题, 2012(12): 91-95.

[21] 西尔克・哈里奇, 比阿特丽斯・普拉萨, 焦怡雪. 创意毕尔巴鄂: 古 根海姆效应 [J]. 国际城市规划, 2012(3): 11-16.
[22] 克劳斯 - 昆兹曼, 唐燕、欧洲和中国的创意城市 [J]. 国际城市规划, 2012(3): 1-5.

[23] 申王铭, 邓秀丽, 任旺兵, 等. 我国创意产业发展的支撑条件评价及空 间发展战略 [J]. 地理研究, 2012(7): 1269-1279.

[24] 盛垒. 北京发展创意产业的战略意义、比较优势及其应对策略 [J]. 北 京社会科学, 2005(3): 72-80.

[25] 厉无畏, 于雪梅. 关于上海文化创意产业基地发展的思考 [J]. 上海经济 研究, 2005(8): 48-53.

[26] 褚劲风. 上海创意产业空间集聚的影响因素分析 [J]. 中国人口、资源 与环境, 2009,19(2): 170-174.

[27] 周春山, 冯莉莉.广州创意产业的发展与布局 [J]. 城市观察, 2009(3): 122-130.

[28] 马仁峰. 大都市创意空间识别研究——基于上海市创意企业分析视 [J]. 地理科学进展, 2012, 31(8): 1013-1023.

[29] 周尚意, 沈小平. 北京美术产业对地方文化的嵌入性程度分析 [J]. 人文 地理, 2008(2): 26-32.

[30] 马仁锋, 沈玉芳. 中国创意产业区理论研究的进展与问题 [J]. 世界地理 研究, 2010(2): 91-101.

[31] 张玥. 全球地方互动与艺术区治理: 以 798 厂和宋庄为例 [J]. 中国治理 评论, 2014(1): 109-122.

[32] 钱紫华, 问小培, 王爱民. 城市文化产业集聚体: 深圳大芬油画 [J]. 热 带地理, 2006(3): 269-274.

[33] 菲利普 - 苏克, 迈克尔 - 韦伯. 创意空间与地方政府：广州红专厂的 案例分析 [J]. 城市观察, 2015, 40(6): 29-39.

[34] 何深静, 钱俊希, 徐雨璇, 等. 快速城市化背景下乡村绅士化的时空演 变特征 [J]. 地理学报, 2012(8): 1044-1056.

[35] 张纯, 王敬窂, 陈平, 等.地方创意环境和实体空间对城市文化创意活 动的影响一以北京市南锣鼓巷为例 [J]. 地理研究, 2008(2): 439-448.

[36] 宋延鹏, 徐逸伦. 文化与商业的平衡: 政府在创意产业园建设中的角 色 [J]. 现代城市研究, 2007(9): 82-87.

[37] Monitoring of Selected Economic Key Data on Culture and Creative Industries 2010[R]. Germany: Federal Ministry of Economics and Technology, 2010

[38] Monitoring of Selected Economic Key Data on Culture and Creative Industries 2011[R]. Germany: Federal Ministry of Economics and Technology, 2011.

[39] Dritter Kreativ-Wirtschafts Bericht[R]. Berlin: Senatsverwaltung für Wirtschaft, Technologie und Forschung, 2013.

[40] Statistisches Jahrbuch 2015[M]. Berlin: Statistisches Landesamt Berlin, 2015.

[41] Burke P. Venice and Amsterdam: A Study of Seventeenth-Century élites[M]. London: Temple Smith, 1974.

[42] 杨波, 陈可石. 谨慎城市更新策略及其实施保障—以柏林施潘道郊 区为例 [J]. 国际城市规划, 2015(S1): 94-99.

[43] 肖雁飞, 曹休宁, 廖双红。创意产业在城市发展中的作用 [J]. 城市问题, 2010(3): 98-101.

[44] 李蕾蕾. 媒介一空间辩证法: 创意城市理论新解 [J]. 人文地理, 2012, 27(4).

[45] Zheng J. 'Creative Industry Clusters' and the 'Entrepreneurial City' of Shanghai[J]. Urban Studies, 2011, 48(16): 3561-3582.

[46] 吴志强. 德国空间规划体系及其发展动态解析 [J]. 国外城市规划, 1999(4): 2-5.

(本文编辑：秦潇雨) 